\title{
Notas para uma pronúncia do francês*
}

César Reis**

RESUMO : Propomos, neste artigo, elementos para discussão a respeito da questão do nível de pronúncia que se deve exigir dos estudantes brasileiros do francês. Denominamos "pronúncia aceitável" aquela que distingue os fonemas da lingua, que não incorpora transferências dos processos fonológicos mais produtivos do português e, finalmente, que não apresenta caracteristicas individuais marcantes. Apresentamos, também, algumas notas sobre a pronúncia do francês.

\section{Introdução}

Parte do conhecimento da língua francesa se refere aos seus fonemas e às suas realizações fonéticas, de acordo com os diferentes contextos ou traços regionais e sociais; características acentuais, rítmicas e entonativas. Trataremos aqui de alguns aspectos da pronúncia do francês. Pretendemos, com isso, ajudar estudantes interessados em melhorar sua pronúncia, assim como alertar estudantes mais avançados sobre eventuais problemas que ainda persistam em sua pronúncia do francês.

\footnotetext{
* Recebido para publicação em maio de 2000.

**Professor do Departamento de Lingüistica da Faculdade de Letras da UFMG.
} 


\section{Pronúncia aceitável}

No que se refere à pronúncia, o professor de francês confrontase com duas questões básicas: Que pronúncia ensinar? Com que níveis de pronúncia trabalhar? Com relação à primeira pergunta, sabe-se, por um lado, que há muita diversidade de pronúncia e, por outro, que umas têm mais prestígio do que outras. No ensino de línguas, seja língua estrangeira ou materna, ensina-se, tradicionalmente, por razões políticas e sócio-econômicas, a modalidade culta do dialeto de maior prestígio. No caso do ensino do francês, língua estrangeira, o francês parisiense culto é considerado o de maior prestígio. Além disso, os métodos de ensino do francês são editados, em grande parte, na França, onde os professores brasileiros fazem também estágios e estudos de aperfeiçoamento. Para essa questão não há na verdade escolha. Ensina-se a pronúncia do método e, em última instância, a pronúncia do professor. A pronúncia do professor, embora, supostamente, parisiense culta, pode sofrer forte interferência da língua materna ou apresentar dificuldades individuais. Se não estudar e aperfeiçoar a pronúncia da língua que ensina, terá problemas no ensino de pronúncia. Essa situação poderá ainda se complicar mais com a crescente cooperação Brasil-Canadá. Situações de ensino do francês em que o dialeto do método de ensino é o francês parisiense coloquial culto e o do professor é o dialeto quebequense coloquial culto poderão se tornar, brevemente, bastante comuns. Como são dois dialetos bem diferentes do ponto de vista da pronúncia, corre-se o risco de o aluno adquirir uma pronúncia com elementos de ambos os dialetos, o que não é desejável.

Com relação à segunda pergunta, relacionada ao nível de pronúncia que se deve esperar de alunos ao final de um curso, penso que, ao invés de definir uma "pronúncia boa", o que é bastante subjetivo, o professor deverá definir um nível de 'pronúncia aceitável', com base em parâmetros objetivos, tais como:

(a) domínio, pelo menos, dos aspectos fonêmicos da língua francesa, isto é, dos contrastes do nível segmental responsáveis pelas 
mudanças de significado de palavras. De acordo com esse parâmetro, a confusão entre [i]/[y] ("la vie'/"la vue') ou entre $[\mathrm{e}] /[\varnothing]$ ('ces'/ 'ceux') não deve persistir na pronúncia do aluno.

(b) eliminação, tanto quanto possível, das transferências negativas do português. Sendo assim, na palavra 'madame', por exemplo, a vogal da sílaba tônica, [da], deve ser pronunciada sem nasalidade [madam] e não como a palavra 'dama' do português, [də̃mı].

(c) finalmente, eliminação, tanto quanto possivel, de problemas de pronúncia que não se relacionem a aspectos estruturais ou de transferência negativa, mas que constituam dificuldades individuais de pronúncia. Por exemplo, o aluno distingue bem as vogais anteriores labializadas e não labializadas. Mas, quando uma labializada ocorre numa palavra, tende a labializar indevidamente toda a palavra. Outro exemplo, a qualidade da vogal anterior semifechada labializada [ø], que aparece na palavra 'peu', [pø], como é um fone novo para o falante do português, pode flutuar entre o [e], [pe] e uma pronúncia mais recuada próxima do [o], [po]. Ou, ainda, o aluno deseja pronunciar o ' $r$ ' parisiense, velar [pari]', mas só consegue pronunciar o ' $r$ ' borguinhão, um tapa, alveolar [pari].

O que consideramos ser a "pronúncia aceitável" se constitui, pois, a partir de elementos desses três parâmetros: é a pronúncia que distingue todos os fonemas da língua alvo, que não transfere os processos fonológicos mais produtivos da língua materna e, finalmente, que não apresenta características individuais muito particulares. Ou seja, uma pronúncia básica, que se deve exigir de todos os estudantes, pelo menos no nível do grupo fônico. Não se pode perder de vista, entretanto, que o nível de pronúncia que se quer atingir é uma questão bastante pessoal, com motivações bem diversas. Dentre os fatores que determinam a qualidade de uma pronúncia (Purcell, 1980), esses três fatores - estrutura

'Nas transcriçðes que se seguem da fricativa uvular, utilizaremos o único simbolo fonético [R], uma vez que são muitas as variantes. 
fonológica da língua materna e da língua alvo, os processos fonológicos da língua materna que são normalmente transferidos para L2 e problemas individuais de pronúncia - devem orientar o professor de língua estrangeira, na sua tarefa de possibilitar a seus alunos atingir a pronúncia aceitável. Há fatores, no entanto, que não pode controlar, como a habilidade individual, o tempo de imersão em L2 e o grau de motivação com relação a uma boa pronúncia da língua estrangeira. Isso explica porque, numa mesma turma, o nível de pronúncia varia tanto de aluno para aluno. De qualquer forma, o professor deverá estar preparado para garantir a 'pronúncia aceitável' para todos e para ajudar aqueles que manifestem um grau maior de exigência a atingirem seus objetivos.

\section{Aspectos da pronúncia do francês}

Sweet (1964:5) já alertava para o que chama de "falácia de imitação". Melhorar o desempenho na pronúncia de uma língua estrangeira exige um treinamento longo e sistematizado. Expomos abaixo algumas generalizações e observações que poderão ajudar o estudante a melhorar a sua pronúncia e, ao mesmo tempo, incentivar o professor de francês a sistematizar os fatos de pronúncia.

\subsection{Vogais médias finais}

Iniciamos nossa exposição sobre alguns aspectos da pronúncia do francês com uma de suas regras mais gerais, que responde à seguinte questão: Qual é a qualidade vocálica da vogal média que se situa na sílaba final do grupo fônico ${ }^{2}$ ?

1. Il était un idiot.

2. Il était mort.

\footnotetext{
2Diante da diversidade teórica, "grupo fönico" nos pareceu a denominaçăo mais neutra para designar o constituinte prosódico imediatamente acima da palavra.
} 
3. Il était tombé.

4. Il était vert.

Para esses casos, existe uma regra bastante geral que mostra que a qualidade da vogal depende da estrutura silábica, que é a seguinte: aberta.

Vogal média em sílaba aberta é fechada; em sílaba fechada é

De acordo, então, com essa regra, as frases acima serão assim pronunciadas:
1. [ iletctẽidjo]
2. [iletemoR]
3. [iletztõbe]
4. [ iletever]

\subsection{Vogais médias não finais}

\subsubsection{Vogais médias posteriores não finais $[0,0]$}

Com relação às vogais que se encontram no interior da palavra, o francês tende a funcionar de forma semelhante ao dialeto baiano, isto é, tende a abrir as vogais. É provável, no entanto, que essa qualidade vocálica seja ligeiramente mais fechada que nossas vogais médias mais abertas.

'tonalité' [ tonalite] 'forcément' [forsemp] 'molesse' [moles] 'occuper' [ okype] 'politique' [politik] 'objet' [obze]

\subsubsection{Vogais médias anteriores não finais $[e, \varepsilon]$}

Contrariamente às vogais médias posteriores, no caso das médias anteriores não finais o [e] é mais freqüente do que o [ $\varepsilon$ ]. Embora a regra 
geral não se aplique de forma tão eficiente como no final de palavra, o estudante poderá tê-la como referência, até confirmação posterior por meio de fonte segura. Não se deve esquecer que, em sílaba aberta, pode ainda ocorrer o [ə]. Ou seja, se a sílaba é fechada, pronúncia-se [ $[\varepsilon]$; em sílaba aberta, pode ocorrer o [ə] ou [e]. Como a ocorrência de um ou outro se situa no nivel lexical, é necessário, para cada palavra, saber se a pronúncia é [ə] ou [e], como veremos na seção 2.5 .

'énergétique' [enerzetik] 'étoile' [etwal] 'leger' [leze]
'idéologie' [ideolozi] 'mercredi' [merkRədi] 'persienne' [persjen]

\subsection{Vogais nasais}

O francês apresenta quatro vogais nasais, [ $\propto \tilde{\jmath} \tilde{\varepsilon} \tilde{\mathrm{D}}$ ], enquanto o português tem cinco [ $i, e, o, u, \tilde{a}]$. É na vogal média posterior labializada que os dois sistemas se aproximam mais foneticamente. A diferença entre o 'bom' do português e o 'bon' do francês é pequena, desprezivel. Em seguida, as vogais que se aproximam mais, mas cuja diferença

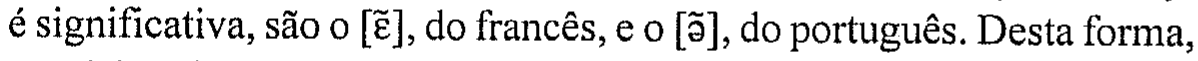
as sílabas finais das palavras 'malsain' e 'maçã' são próximas foneticamente. A vogal do francês é, entretanto, mais anterior. Quanto à apertura, a vogal do francês parece ser ligeiramente mais aberta. Mas é preciso confirmar isso através de documentos da Fonética Articulatória. Sendo assim, as vogais do francês que mais poderão causar dificuldades são [œ $\tilde{\text { p̃}}]$.

Entretanto, o sistema francês de quatro vogais nasais, que aparecem todas, na ordem apresentada acima, na frase 'un bon vin blanc [œ bõ v vह blĩ] está perdendo a primeira dessas vogais, [œ], mesmo em dialetos da região parisiense (Walter, 1982). Essa vogal vem sendo substituída por

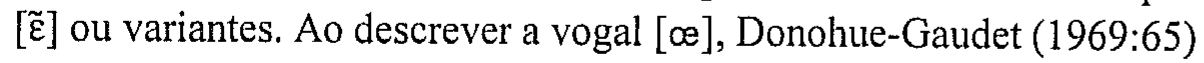

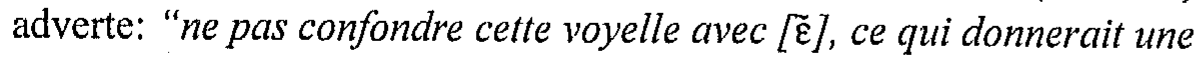
prononciation populaire". O estudante iniciante tenderá pronunciar 
palavras como 'bain', 'banc' e 'main', 'ment' da seguinte forma: utilizando a vogal [e] (de 'dente') para formas como 'bain' e 'main" e o [ã] (de 'manta') para formas como 'banc' e 'ment'. Ora, na verdade, a realização [ã] é mais apropriada para 'bain' e 'main'. Não percebe, talvez por influência da escrita, que a qualidade da vogal da palavra 'banc' e 'ment',

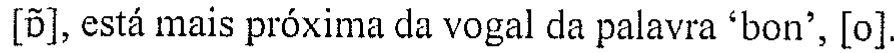

Resumindo, como a pronúncia da vogal [œ] é considerada difícil para o estudante brasileiro, pode ser eliminada, uma vez que não mais

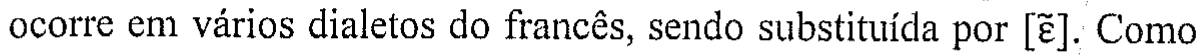
vimos, pode-se chegar à pronúncia dessa última vogal a partir do [ã] do português, pronunciando-se as palavras 'vin' e 'vain', por exemplo, da

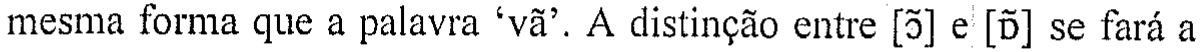

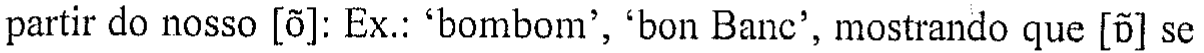
diferencia de [õ] pelo fato de ser mais aberta, sendo ambas recuadas.

\subsection{Juntando as palavras}

No francês, muito freqüientemente as palavras terminam por consoante, quando pronunciadas isoladamente. $O$ que favorece, na fala, um processo de ressilabificação, quando a palavra seguinte começa por vogal. Ex: 'avec elle' [a.ve.kel]. 'il est là' [i.le.la], 'une petite amie' [yn.pti.ta.mi], 'sur une table' [sy.ryn.tabl], ' quatre enfants' [ka.trõ.fõ]. Deve-se, pois, proceder a essas reestruturações silábicas que acontecem no grupo fônico, não se conservando as estruturas silábicas do nível da palavra isolada. Ex: [a.vek.el], [il.e.la], [yn.pə.tit.ami], [ syr.yn.tabl],

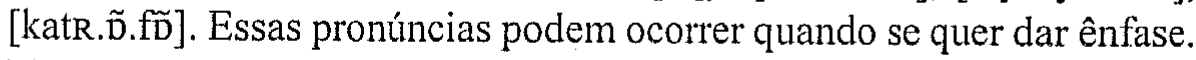
Na pronúncia do estrangeiro, deve-se à hiperarticulação, à influência da escrita ou ao desconhecimento de processos fonológicos do francês.

No português existe o mesmo processo fonológico, sendo, entretanto, reduzido o número de consoantes em posição final de sílaba $(1, \mathrm{r}, \mathrm{s})$. Ex.: 'as outras' [e.zou.tres], 'por aqui' [pu.re.ki]. ${ }^{3}$ Como as outras consoantes não ocorrem em final de sílaba, há sempre a tendência de se produzir uma vogal após a consoante em posição final de grupo fônico. 


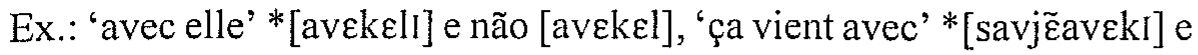
não [savjẽavek].

No português, o fricativo alveolar [s], que é não vozeado, passa a vozeado num contexto vozeado: Ex;'mesmo' [mezmu], Bósnia [boznie]. Em francês, essa regra não se aplica: 'Islam' [islam], tourisme [tuRism] 'Bosnie' [bosni]. 'immobilisme' [imobilism], 'communisme' [komynism]. A transferência negativa mais conhecida, entretanto, é a da assimilação da nasalidade, que acontece no português e não acontece no francês, pelo menos no francês coloquial parisiense culto. Ex.: em português: 'solene' [solent], Colônia [kolonie]; em francês, 'soudaine'[suden], [koloj ].

\subsection{O "e instable"}

Um dos aspectos mais interessantes da pronúncia do francês é o chamado "e instable", também chamado de "e muet", "e caduc", "e féminin", "e neutre", "voyelle latente", "schwa".

Dominar as regras que controlam essa vogal camaleônica constituise talvez num dos últimos estágios na aprendizagem da pronúncia do francês. É provável que o estrangeiro com boa pronúncia do francês não domine completamente as regras que controlam o uso dessa vogal instável. Mas alguma coisa sobre o uso do "e instable" é possível aprender já nos primeiros estágios do processo de aprendizagem, seja no nível lexical, seja no nível do grupo fônico. Como os contextos segmental e prosódico são bem definidos no nível do grupo fônico, pode-se estudar aí o funcionamento do "e instable", assim como propor todo um treinamento de pronúncia, cabendo ao professor de francês determinar o tempo necessário para que o aluno domine esse aspecto da pronúncia.

\footnotetext{
${ }^{3}$ No caso das palavras terminadas por $/ /$, esse processo ocorre no nivel da palavra de um jeito: 'sal' $\Rightarrow$ 'saleiro', 'mal' $\Rightarrow$ 'malicia' e, no nível da frase, de outro: 'sal' b [sa.wa.kij]. Con o $/ \mathrm{R} /$, há normalmente a passagem da lricativa para um tapa: Ex.: mar, maré, mar azul [mah], [Mare], [marəzu:]. Jả no/s/ só muda o vozeanento.
} 
É na região anterior média que o francês apresenta o maior número de distinções vocálicas: [e $\varepsilon$ œ ə] ]. A distinção entre o [ə] e os fones não labializados é nítida, pois o "e instable" é labializado, enquanto as vogais $[e, \varepsilon]$, não são labializadas. Já com os labializados, e sobretudo com o [œ], a diferença é mais sutil. Donohue-Gaudet apresenta assim as características articulatórias dessa vogal, que, pela precisão, embora longa, transcrevemos abaixo:

C'est une voyelle labiale. Les lèvres sont projetées comme pour prononcer l'œ ouvert. La pointe de la langue est pressée contre les incisives inférieures et le dos de la langue est sensiblement dans la position requise pour l' $\varepsilon$ ouvert. Le timbre de l'a caduc et sa durée peuvent varier selon la position de la voyelle par rapport à l'accent dans le groupe phonétique. Le plus souvent on les rapprochera de ceux de l'œ ouvert inaccentuée:

par exemple: petit peureux

$\ni \propto \varnothing$

Nos expériences en phonétique expérimentale ont démontré une durée moyenne de 8 à 10 centisecondes. Cette durée ne devra pas être raccourcie et la labialité sera plutôt exagérée pour ne pas confondre $ə$ avec e fermé, $\varepsilon$ ouvert et même a antérieur. La langue ne doit pas articuler trop en arriére sinon l'a caduc deviendrait une sorte de o. (DONOHUE-GAUDET, 1969:53).

Se pudermos acrescentar alguma coisa a uma descrição articulatória tão precisa, diremos que há pelo menos um argumento de natureza morfofonológica que poderia ser usado para fundamentar a apertura, [ع], proposta pelo autor para o [ə]: em verbos como 'lever' [love], em que as três primeiras pessoas do singular do indicativo presente e a $3 \mathrm{a}$. do plural têm uma única sílaba, a qualidade da vogal é exatamente a proposta por Donohue-Gaudet: 'lève' [lev], uma vez que o "e instable" não aparece em posição tônica.

Léon (1992:141), entretanto, mais atento às variações de pronúncia do francês, afirma que a qualidade do "e instable" pode variar "fluctuant selon les régions, les individus ou le contexte". Em Paris, conforme descreveu Donohue-Gaudet, é mais aberto, sendo a frase 'prends-le' pronunciada da seguinte forma: [pRõlœ], mas, nos dialetos do Norte, seria pronunciado [pRõlø]. 
Alguns autores não distinguem [ə œ]. O que diferencia esses fonemas, segundo Tranel (1987) é que um deles pode desaparecer, /ə/, enquanto o outro, /œ/, não. Assim, segundo esse autor, as frases: a) "dans le rétablissement" ("no restabelecimento') e b) "dans leur établissement" ('no estabelecimento deles'). podem ter a mesma pronúncia: [dõlœRetablismõ]. Acontece, no entanto, que, em a), o /a/ pode cair: [dõlretablismo]. enquanto que em b) nunca cai.

O que podemos, então, saber já nos primeiros anos de estudo do francês sobre essa vogal? Temos de distinguir duas questões diferentes: a primeira se refere ao fato de uma palavra determinada possuir ou não o "e instable". As palavras 'dessus', 'métro', 'effort' pronunciam-se com [e] ou com [ə]? Se a responta é: a palavra se pronuncia com o "e instable", a segunda pergunta que se segue naturalmente é a seguinte: o "e instable" se pronuncia ou não? Ou seja pronuncio 'il est dessus' [iledosy] ou [iledsy]? A resposta à primeira pergunta situa-se no nível do léxico. Trata-se de uma informação que se aprende com a palavra. Com esse conhecimento lexical, o aluno evitará problemas de comunicação, já que o "e instable" é um fonema no francês. Deverá, pois, distinguir 'il est dessus' [iledosy] de 'il est déçu' [iledesy] ou 'le petit pleurait' [ləptiplœR $\varepsilon$ ] e 'les petits pleuraient' [leptiplœR ] . Fora desses contextos, o uso de um pelo outro poderá ainda criar dificuldades de comunicação, além de evidenciar o sotaque estrangeiro. $\mathrm{O}$ aluno do francês normalmente se apóia na escrita para saber se o "e" é instável ou não. Se a letra "e" apresenta um acento ("métis"), vem seguida de duas consoantes, pronunciadas ou não ("greffer", "inepte", "inexorable") ou seguida de consoante na mesma sílaba ("tester"), não representa um "e instable". Isso ajuda, evidentemente, mas penso que o professor deve incitar o aluno a discriminar a qualidade da vogal auditivamente.

Ainda no nível da palavra, podemos começar com três princípios:

1) No início de palavra, o "e instable" nunca aparece.

2) No final de palavra isolada, o "e instable" aparece raramente no dialeto parisiense culto. Mas é uma das características mais marcantes do dialeto do sul da França: 'responsable' [Respõsabl]/ [Respõsablə]. 
3) No meio de palavra, muitas vezes não é fácil saber qual é a qualidade dessa vogal anterior média. A qualidade dessa vogal, aprende-se com a palavra. Mesmo aqui, se a sílaba é travada, o "e instable" não aparece: 'rester' [Reste], 'mistère' [mister], 'cette' [set], 'mercredi' [merkradi].

Já a segunda questão, que se relaciona à pronúncia ou não do "e instable", é muito mais complexa e se relaciona com o ritmo e a prosódia. Apenas algumas generalizações são possíveis no nível do grupo fônico.

Em razão da famosa regra que evita uma seqüência de três consoantes no francês, o "e instable" é pronunciado: "le merle bleu" / [lomerlo blø], "une double vie"/ [yndublovi].

No exemplo seguinte, a palavra "course" não apresenta o "e instable" na primeira ocorrência, mas, na segunda, aparece para evitar a seqüência de três consoantes e, talvez, também para enfatizar: 'Parlons de la

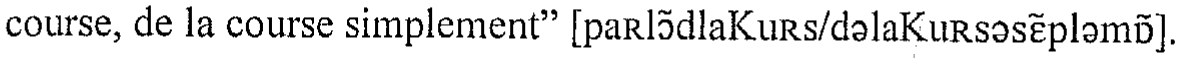

Price (1991:78-79) apresenta quatro regras para o uso do "e instable" no nível do grupo fônico:

Regra 1: no final do grupo, o /ə/ não é pronunciado no dialeto parisiense do francês. Ex.: 'la porte' [laport], 'trop vaste' [trovast], 'les Alpes' [lezalp].

Regra 2: na primeira sílaba do grupo,/ə/ é normalmente pronunciado. Ex.: 'de quelle manière' [dəkelmanic:R], 'je sais' [3əse], 'le beau livre' [lobolive].

Regra 3: no meio do grupo, o "e instable" não é normalmente pronunciado, se precedido por uma única consoante. Ex.: mais je veux le faire [mezvølfer], 'vous le verrez' [vulvere].

Regra 4: no meio do grupo, o "e instable" é normalmente pronunciado, se precedido por duas ou mais consoantes. Ex.: 'car je le dirai' [Karzoldire], 'justement' [3ystəmõ]. 
Existem ainda alguns aspectos curiosos a respeito do "e instable":

Nos verbos como 'venir' e 'tenir', o [ə] é pronunciado com freqüência [vəniR], [təniR]. No verbo 'mener' praticamente nunca desaparece [məne]. Desaparecem, entretanto, nos seus derivados: 'souvenir', 'revenir', 'devenir', 'soutenir', 'maintenir', 'emmener', 'amener',

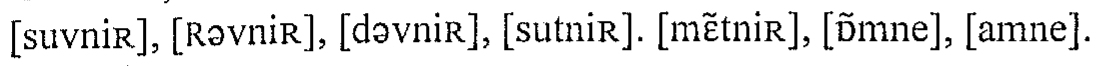

Em algumas palavras o "e instable" cai mais freqüentemente: 'rejeter', 'rejeton', 'lâcheté', 'échelon', 'écheveau', 'canevas', 'peloton'. 'élever', 'museler', 'fuselage', 'osselet', 'ruisselant', [Rәзte], [Rәztõ], [lafte], [eflõ], [efvo], [kanva], [plotõ], [elve], [myzle], [fyzlaz], [osle],

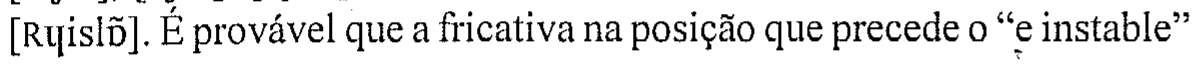
favoreça sua queda. Mas como em contextos como esses, como com a fricativa [S], em palavras como 'chenal' [Sənal], o "e instable" é, ao contrário, bastante estável, outros fatores devem interferir, como o ritmo. Outro fato interessante é que em palavras que terminam em 'ier'/'ière'

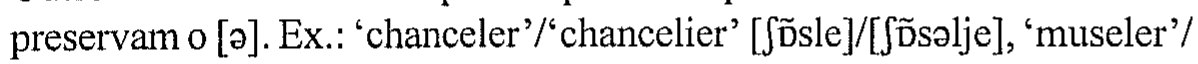
'muselière' [myzle]/[myzaljer].

\subsection{A "liaison"}

Vários processos fonológicos afetam a fronteira entre duas palavras. Entre eles o mais característico do francês chama-se "liaison", ligação, que não deve se confundir com o "enchaînement", encadeamento, e com a "élision", queda de vogal ou elisão. Vamos primeiro deixar claro o que significam os dois últimos processos fonológicos. Começando pela 'elisão', que é, na verdade, um processo morfofonológico: em um pequeno número de morfemas gramaticais, na maioria monossilábicos, a vogal cai, quando seguida de palavra iniciada por vogal. Ex: la + armoire $\Rightarrow$ l'armoire; que + il $\Rightarrow$ qu'il; si + il $\Rightarrow$ s'il. O encadeamento é o processo mais geral, que, na verdade, engloba também a ligação, pois acontece sempre que uma palavra que termina com consoante vai sofrer uma reestruturação silábica, quando a palavra seguinte se inicia por vogal. Ex.: 'quatre enfants' [KatRõf̃̃], 'tête énorme' 
[tztenoRm], 'par avion' [paravjõ]. Costuma-se, entretanto, distinguir o encadeamento da ligação, porque, no encadeamento, a consoante da primeira palavra é sempre pronunciada, qualquer que seja o contexto. Ex.: 'quatre fils' / 'quatre élèves' [katrfis], [katRelev]; 'par bateau' / 'par avion' [parbato], [paravjõ]. Já na ligação a consoante da palavra que precede só é pronunciada se a palavra seguinte se inicia por vogal. Caso contrário, essa consoante não é pronunciada. Ex.: 'des amis'//des filles'

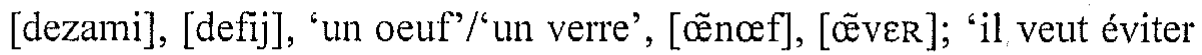
cela' / 'il veut partager cela' [ilvøtevitesla], [ilvøpartazesla]. Em resumo, podemos ilustrar os dois processos 'encadeamento' e 'ligação', a partir do artigo indefinido:
a. une amie
[y.na.mi]
b. une fille
[yn.fij]

Neste caso, houve um 'encadeamento', porque: primeiro, a consoante final da primeira palavra aparece sempre, em qualquer contexto, isto é, seja vogal ou consoante o primeiro fone da palavra seguinte; segundo, quando a palavra seguinte, como em a., começa por vogal, há a ressilabificação que dá origem ao encadeamento. Examinemos agora os exemplos abaixo:
c. un ami [थ̃.na.mi]
d. un garçon [ãe.gaR.sõ]

Neste caso, a consoante final da primeira palavra só aparece no contexto em que a palavra seguinte começa por vogal, como em c., ocorrendo aí a ressilabificação. Já em d. não há a presença de consoante na primeira palavra, porque a palavra seguinte começa por consoante.Vamos chamar essa consoante que pode ou não ser pronunciada de 'consoante latente'. Esse caso especial de encadeamento é chamado de ligação.

Outros exemplos de encadeamento:

Le principal accusé

La troisième étape

Tué par balle hier

Une chaîne alimentaire humaine [la]

[me]

[ljeR]

[na] [Ry] 
Podem no mesmo lugar acontecer uma ou mais ligações na mesma frase. O que mais ocorre é uma ligação na frase. Mas duas e até três podem também ocorrer.

Exemplos com uma ligação (os pontos de ligação serão marcados com o sinal $\cup$ e serão transcritas apenas a última sílaba da primeira palavra e a primeira sílaba da palavra seguinte que resultou do processo de ligação):

Cela pourraituêtre possible.

[RE.tetR]

Partout $\cup$ ailleurs

[tu.taj]

Ils se fontuentendre

[fõ.tñ]

Euxuaussi

[ø.zo]

Il estuurgent

Il se cachentuencore

[le.tyR]

Cetuindividu

[kas.tõ]

Les petites Uentreprises

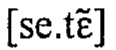

Des traditions $\cup$ anciennes

[ti.tz̃̃ ]

[sjõ.z̃̃ ]

As ligações não são todas de mesma natureza. Podem ser obrigató-

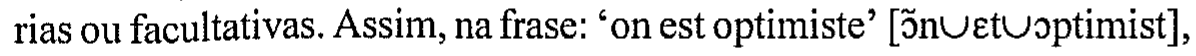
a primeira é obrigatória e a segunda é optativa.

Outros exemplos de duas ligações numa mesma frase:

Quand Uilsuacceptent

Ils lesUontuemmenés

Il restaituun vinterlocuteur

Dansuunuinstant

Comment envestuon arrivé là

Ilsuétaientuune cinquantaine

Onvenvest loin

Conformémentuà cesuaccords

Cesuopérationsuaériennes [ti] [za]

[zõ] [tõ $]$

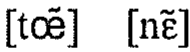

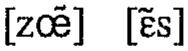

[nE] [t̃̃]

[ze] [tyn]

[no] [nE]

[ta] [za]

[zo] [za]

Exemplos com três ligações na mesma frase:

Onuenvestuà la troisième

[ñ̃] [ne] [ta] 
Exemplos de ocorrência de ligação e encadeamento numa mesma frase (o encadeamento será representado por um traço-):

Peutvon être-un révolutionnaire?

Devantuune-école.

Aprèsuavoi-entendu

Il vontUêtre-envoyés [tõ] [tRœ̃]]

[ty] [ne]

[za] [R̃̃]

$[\mathrm{t \varepsilon}] \quad[\mathrm{tR} \tilde{\mathrm{D}}]$

Exemplo de encadeamento e ligação numa mesma frase:

\section{L'air-estuirrespirable}

[RE] [ti]

A ligação pode ocorrer, às vezes, até quando há uma pausa entre as palavras, tornando-se, assim, elemento de ênfase:

C'est (pausa) extrêmement difficile [š/tøkstremmõdifisil]

São muitos os fatores, rítmicos, dialetais, sociolingüísticos e estilísticos, que controlam o funcionamento da ligação. Para citar apenas um deles, o estilístico, na frase "Vous, les femmes actives avez agi" o fenômeno da ligação se comportaria da seguinte forma:

\section{Poésie:}

Vous, les femmesuactives $\cup$ avezuagi. [za] [za] [za]

Conférence:

Vous, les femmesuactives avezuagi. [za]

[za]

Conversation soignée: Vous, les femmesuactives avez agi. [za]

Conversation familière: Vous, les femmes actives avez agi.

O que ocorre também com muita frequêencia é a chamada 'ligação sem encadeamento'. Neste caso, a consoante latente é pronunciada, mas não há reestruturação silábica. Normalmente, ocorre uma pausa entre as palavras (Cf. ENCREVÉ, 1988).

Ce sont (pausa) eux qui les on vus.

Ils n'ont (pausa) aucun compte...

Les attentes sont (pausa) immenses.

Cette négociation qui est (pausa) ardue...

Il avait (pausa) admirablement...

Tout cela se briserait (pausa) en nous.

Je suis (pausa) irrécupérable.

[səsõt/økilezəvy]

[inว̃t/okœkõt]

[lezatõtsõt/imñ̃s]

[setnegosjasjõkiet/ardy]

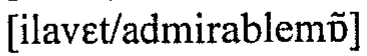

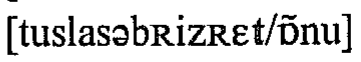
[3əsuiz/iRekyperabl] 
A ocorrência ou não da ligação pode afetar o significado. Ex.: peutuêtre, 'talvez'; peut être, 'pode ser'.

\subsection{Alguns casos particulares}

Vamos tratar agora de alguns aspectos mais particulares nos quais as semelhanças fonéticas podem induzir a erro de pronúncia:

Os itens léxicos são semelhantes nas duas línguas, mas o radical apresenta pelo menos um fonema distinto (leia-se: som ou palavra francesa/som ou palavra portuguesa):

$\left[\int\right] /[\mathrm{k}]: \quad$ "machine"/máquina; "chimie"/química, "architecte"/ arquiteto, "archipel"/arquipélago;

[S]/[s]: "archevêque"/arcebispo, "chirurgie"/cirurgia;

$[\mathrm{gz}] /[\mathrm{z}]: \quad$ "exactement"/exatamente, "exemple"/exemplo,

$[\mathrm{ks}] /[\mathrm{s}]:$ "texte"/texto, "maximum"/máximo;

$[\mathrm{z}] /[\mathrm{s}]:$ "musulman"/muçulmano

ou, inversamente,

$[\mathrm{s}] /[\mathrm{z}]:$ "coalition"/coalisão.

A pista ortográfica resulta numa pronúncia errada da palavra francesa: "second", zinc, cujo 'c' se pronuncia [g]; Em immanquable, immangeable, a sílaba inicial pronuncia-se $[\tilde{\varepsilon}]$, contrariamente ao que acontece com as palavras que começam com esse prefixo, como 'immobilisme', 'imminent', 'immatériel', 'immuable', etc... que se pronúncia com [i]. Valendo o mesmo para 'innommable', 'illisible' et 'irresponsable'. Trata-se, aqui, de um aspecto morfofonológico do francês, em que, do ponto de vista diacrônico, a consoante do prefixo "in" sofreu um processo de assimilação diante de uma classe de consoantes soantes. Podemos, de um ponto de vista sincrônico, simplesmente dizer, que esse prefixo se pronuncia [i] diante das consoantes $[\mathrm{m}, \mathrm{n}, \mathrm{l}, \mathrm{R}]$ e $[\tilde{\varepsilon}]$ diante das palavras que se iniciam com outras consoantes. Ex.: 
'imperméable', 'incertain', 'introuvable'. Provavelmente, as palavras 'immanquable' e 'immangeable', são pronunciadas assim, porque são de formação mais recente. Como explicar ainda palavras como 'inaccentuée', 'inébranlable', 'inhabile' [inaksõtye] [inebrõlabl] [inabil]? Neste contexto, ou seja, diante de palavra iniciada por vogal, o prefixo apresenta sua forma original [in].

Da mesma forma, palavras iniciadas por 'em' e 'en', pronunciam-

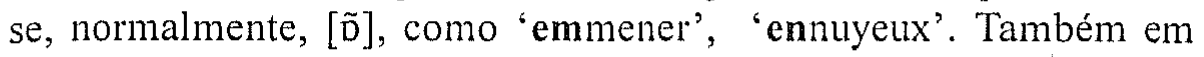
palavras como 'enivrer' e 'enorgueillir', pronuncia-se [̃̃nivre],

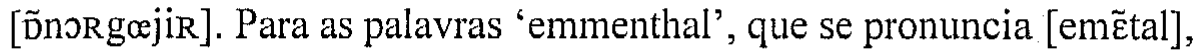
com pronúncia particular também para a segunda sílaba, e para a palavra 'ennemi', que se pronúncia [enmi]. Nesses casos, a pista ortográfica pode confundir.

Depois que se aprendeu que 'gn', em francês, corresponde ao nosso 'nh', 'montagne', 'ligne', deve-se saber que em algumas palavras o dígrafo 'gn' se pronúncia como uma seqüência de sons [gn] e não como 'nh'. Ex.: 'estagnation' [stagnasjõ]; 'magnitude' [magnityd]. Da mesma forma, se a seqüência ortográfica 'll' se pronuncia normalmente [ij], como em 'bille', 'pastille', etc..., nas palavras 'distiller', 'ville', 'osciller', 'mille', 'villa' pronuncia-se [1], [distile], [vil], [osile], [mil], [vila].

Bastante curioso também, e bem diferente do português, é a maneira como se pronunciam palavras do inglês. É sabido que o lugar original do acento nunca é respeitado, acentuandó-se sempre a última sílaba. $\mathrm{O}$ que é menos observado, no entanto, são modificações no nível segmental. Ex.: 'leader' [lidœR], 'slow' [slo], 'jokey' [30ke], 'business' [biznes], 'barman' [barman].

O fone $[\mathrm{k}]$ aparece freqüentemente em posição final de sílaba, como em 'perfection', 'protection', 'architecte', 'verdict', 'musique', 'fantastique', 'bac', 'impact', 'bec'. Mas, em algumas palavras, a letra 'c' não representa qualquer som. Ex: 'tabac', 'estomac', 'accroc', 'escroc', 'blanc', 'franc', 'jonc', 'broc', 'aspect', 'respect', 'instinct',

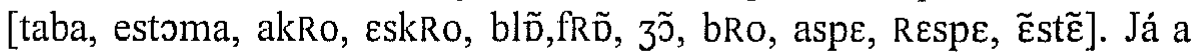
palavra 'exact' et 'inexact' admitem as pronúncias [Egzakt]/[Egza], [inegzakt]/[inegza]. 
Na sua forma infinitiva, $[R]$ não se pronuncia em verbos terminados por /eR/: 'voyageR' [vwaze], 'tRouver' [tRuve], mas pronúncia-se nas outras conjugações: 'revoir' [RəvwaR], 'dormir' [doRmiR]. No português, a pronúncia do " $R$ " na forma infinitiva ocorre normalmente no estilo formal, mas desaparece na fala coloquial, em todas as conjugações.

\title{
3. Conclusão
}

Ao ensinar a língua francesa, o professor deve fixar seus objetivos no que se refere à pronúncia. Diferentes estágios no processo de aprendizagem da pronúncia devem ser estabelecidos, de acordo com as características do curso. O que denominamos de 'pronúncia aceitável' é o nivel de pronúncia básico, que todo estudante de francês deveria atingir, para uma comunicação eficaz. O ensino de pronúncia baseado no conhecimento fonético/fonológico, acelera o processo, aprimora os resultados e possibilita, ainda, uma reflexão lingüística.

\begin{abstract}
RÉSUMÉ : Nous proposons, dans cet article, des éléments pour une discussion à propos de la question du niveau de prononciation qu'un étudiant brésilien doit atteindre. Nous parlons de "prononciation acceptable", c'est-à-dire, une prononciation dont les phonèmes de la langue sont bien distingués, une prononciation qui ne présente ni de transfert de procès phonologiques les plus productifs ni de caractéristiques individuelles trop particulières. Nous présentons, finalement, quelques notes sur la prononciation du français.
\end{abstract}

\section{Referências Bibliográficas}

DONOHUE-GAUDET, M.-L. Le Vocalisme et le Consonantisme Français. Paris: Delagrave, 1969.

ENCREVÉ, P. La Liaison avec et sans Enchaînement. Paris: Seuil, 1998.

LÉON, P. R. Phonétisme et Prononciations du Français. Paris: Nathan, 1992. 
TRANEL, B. The Sounds of French. Cambridge: Cambridge University Press, 1987. PRICE, G. An Introduction to French Promunciation. Oxford: Blackwell. 1991.

PURCELL, E. T. PURCELL, R. W. "Predictor of pronunciation accuracy. A reexamination." Langague Learning, 30, 1980.

SWEET, H. The Practical Study of Languages. London: Oxford University Press, 1964.

WALTER, H. Enquête Phonologique et Variélés Régionales du Français. Paris: PUF, 1982. 